\title{
A C0P-15 sob holofotes mediáticos: modos e níveis de intervenção política do jornalismo no sistema de mídia brasileiro
}

\author{
Diógenes Lycarião Barreto de Sousa e Rousiley Celi Moreira Maia
}

\section{Resumo}

A variável "paralelismo político" tem sido recorrente na análise comparativa de sistemas mediáticos. № entanto, recentemente, ela tem sido alvo de diversas críticas. Para fundamentar esse tipo de contestação, os sistemas de mídia brasileiro e de países em desenvolvimento têm sido referenciados como exemplos de um modo ativo, mas não necessariamente político-partidário de intervenção política. Esta pesquisa, por um lado, oferece evidências empíricas nesse sentido, especificamente para os centros de visibilidade e de qualidade jornalística do sistema de mídia brasileiro (JN e FSP, respectivamente). Por outro, também se demonstrou que esse desempenho assume diferentes modos e intensidades entre os centros em questão. Entre a FSP ( $n=65)$ e 0 JN $(n=21)$, foi possível perceber diferenças substantivas na quantidade $\mathrm{e}$ qualidade do papel advocatício das práticas jornalísticas na cobertura da COP-15. Ao mesmo tempo, o caráter ativo se manteve praticamente estável. Implicações teóricas e metodológicas para pesquisas futuras são discutidas.

\section{Palavras-Chave}

Paralelismo político. COP-15. Sistema mediático. Jornalismo brasileiro.

\section{Diógenes Lycarião Barreto de Sousa}

dramarc_leon@yahoo.com.br I Doutor em Comunicação social pela Universidade Federal de Minas Gerais - UFMG. Realiza PósDoutorado na Universidade Federal Fluminense - UFF.

Rousiley Celi Moreira Maia | rousiley@yahoo.com.br Doutora em Ciência Política pela University of Nottingham - Inglaterra. Pós-Doutora pela Boston College - EUA. Professora da Universidade Federal de Minas Gerais - UFMG.

\section{Introdução}

0 nível da intervenção política dos sistemas mediáticos na vida pública tem sido alvo de intenso debate na literatura especializada (ALBUQUERQUE, 2012; 2005; AZEVED0, 2006; DONSBACH \& PATTERSON, 2004; HALLIN \& MANCINI, 2012; HANITZSCH et al., 2011; WESSLER et al., 2008).

No âmbito desse debate, uma das principais preocupações gira em torno do desafio de se comparar os padrões desse tipo de intervenção entre sistemas mediáticos de diferentes países.

No seio desse debate, encontra-se a variável "paralelismo político". Ela foi utilizada por Hallin e Manicini (2004) a fim de servir ao tipo de comparação em tela. Contudo, esta variável passou a receber diversas críticas, notadamente de Albuquerque (2012). Diante delas, os autores de "Comparing Media Systems" reconhecem a potencialidade de se analisar a intervenção política do jornalismo sob a abordagem proposta por Albuquerque, a qual consiste em estudar 0 papel ativo dos sistemas mediáticos em função dos sistemas políticos. 
Neste artigo, argumentamos que a forma com que esse papel ativo tem sido descrito pode estar subsumindo dimensões da intervenção política do jornalismo. Para tanto, exploramos a proposição de Donsbach e Patterson (2004) de que o jornalismo ativo e o advocatício seriam dimensões diferenciadas da intervenção política realizada pelas práticas jornalísticas.

De modo a testar esse argumento, conduzimos 0 presente estudo de caso. Guiamo-nos pela seguinte questão: a análise diferenciada entre "jornalismo ativo" e "jornalismo advocatício" é capaz de descrever, com maior fidedignidade, 0 desempenho do sistema mediático brasileiro do que aquelas derivadas da noção de "paralelismo político"?

A fim de explorar esse problema, optamos por investigar, mediante análise interpretativa e de conteúdo, a cobertura brasileira da COP15 , sendo esta uma abreviação para a $15^{\mathrm{a}}$ Conferência da Convenção-Quadro das Nações Unidas para Mudanças Climáticas (UNFCCC, em inglês). A COP-15 foi realizada em dezembro de 2009, em Copenhague (Dinamarca), tendo sido o evento que produziu o maior pico de grande visibilidade em torno da questão das mudanças climáticas nos últimos anos ${ }^{1}$. A codificação se deu sobre a cobertura do Jornal Nacional (JN) e da Folha de S. Paulo (FSP), considerados como sendo, respectivamente, os centros de visibilidade e de qualidade jornalística do sistema mediático brasileiro. Ao todo, 86 matérias foram avaliadas.

Esse estudo contribui para evidenciar as nuances que estão por trás da ideia de "intervenção política" das práticas jornalísticas. Nesse sentido, a análise orientada para captar a diferença entre "jornalismo ativo" e "jornalismo advocatício" mostrou-se produtiva. Isso porque estabelecer tal diferenciação nos possibilitou descrever 0 desempenho do sistema mediático brasileiro com maior fidedignidade do que a noção de "paralelismo político" permitiria fazer.

Outra contribuição de nosso estudo referese à apresentação de evidências do caráter advocatício do jornalismo, dando a ver distintos níveis de intervenção entre os centros do sistema mediático brasileiro. Nessa escala, o centro mais fraco, em termos de caráter advocatício, seria o JN. Em posição intermediária, estaria a FSP. 0 mais forte, a $\mathrm{Veja}^{2}$.

Este artigo está organizado da seguinte forma: as duas próximas seções exploram as questões teóricas que motivaram a condução dessa investigação. A quarta oferece um panorama do estudo de caso e dos procedimentos metodológicos utilizados. Na quinta, são apresentados os resultados. Na sexta e última seção, são apresentadas, além da discussão dos resultados, indicações para pesquisas futuras. 


\section{Limites da variável "paralelismo político"}

Em sua contribuição para o livro Comparing

Media Systems Beyond the Western World, Albuquerque apresentou diversas ponderações críticas sobre a variável "paralelismo político", uma das categorias centrais utilizadas por Hallin e Mancini (2004) para desenvolver o estudo comparativo de sistemas mediáticos. Para sustentar a perspectiva de que essa variável apresenta severas limitações para comparações fidedignas à complexidade e à diversidade dos sistemas mediáticos, 0 autor brasileiro toma como exemplo justamente 0 caso do sistema midiático nacional. Na visão de Albuquerque, a variável "paralelismo político" tem sua validade limitada a contextos em que há relações estáveis entre veículos de comunicação e elites políticas, ou, pelo menos, entre esses meios e orientações ideológicas tradicionais (da direita à esquerda, por exemplo). Essa variável seria, portanto, débil para identificar e analisar o caráter ativo que a imprensa pode assumir de modo flexível e instável. Um modo que não está necessariamente ligado a uma corrente de valores políticos ideológicos à esquerda ou à direita.

Ainda segundo 0 autor, a retórica da prática jornalística brasileira seria exemplar nesse sentido, pois ela atuaria através de um posicionamento político em relação ao jogo político, só que não em nome de uma visão ideológica nem de determinados setores sociais, mas, sim, em nome do próprio interesse público.

Tal comportamento seria próximo, portanto, ao da retórica estadunidense de vigilante crítico (watchdog) do sistema político (ALBUQUERQUE, 2005, p.487). 0 sistema mediático brasileiro, todavia, na visão de Albuquerque, ultrapassaria as aspirações dessa retórica, uma vez que 0 jornalismo brasileiro reivindicaria a prerrogativa de intervir no jogo político em nome dos interesses nacionais. Desse modo, o sistema midiático assumiria o papel de árbitro das disputas políticas setoriais vinculadas a ideologias partidárias ou mesmo a instituições do sistema político. Por consequência, essa atuação se daria de forma ambivalente em relação ao ordenamento institucional da democracia liberal, encontrando na concepção de "Poder Moderador" uma linha de continuidade histórica para esse tipo de intervenção no jogo político:

Argumento que uma atitude ambivalente com
relação às instituições políticas liberais tem sido
uma característica permanente da vida pública
brasileira e, em muitas ocasiões, diferentes
instituições se candidataram (ou foram convi-
dadas) a desempenhar o papel de um "quarto
poder". Sugiro que, principalmente a partir dos
anos 1980, a imprensa reivindicou para si esse
papel, recorrendo, para justificar suas reivindi-
Cações, a uma retórica norte-americana. (ALBU-
QUERQUE, 2005, p.487 - tradução nossa)
QUERQUE, 2005, p.487 - tradução nossa)

Seria possível, assim, perceber, no sistema informativo dos media brasileiro, uma coexistência entre uma cobertura pluralista/ equilibrada e uma atuação ativa/advocatícia (ver AZEVED0, 2006). Outros estudos corroboram 
a percepção de que essa coexistência ultrapassa os períodos eleitorais e faz parte de debates públicos mediados (ver MAIA, 2009; MIOLA 2012). Este é 0 argumento central defendido por Albuquerque (2005, 2012).

No debate sobre a abordagem comparativa dos sistemas midiáticos, 0 argumento em questão se mostra fecundo para propiciar revisões em relação à variável "paralelismo político". A necessidade dessa revisão é inclusive reconhecida por Hallin e Mancini:

\begin{abstract}
A proposta de Albuquerque em desagregar 0 conceito de paralelismo político e, em particular, de separar o pluralismo externo - ou seja, a tendência dos diferentes meios de comunicação em se alinhar a diferentes tendências partidárias - do papel ativo dos meios de comunicação - 0 qual se refere à tendência da mídia de intervir na vida política, de se envolver partidariamente, ou de tentar influenciar os acontecimentos políticos - parece ser uma ideia potencialmente valiosa, e que se encaixa nos achados de outros colaboradores, incluindo Balcytiené e McCargo. Assim como no caso do profissionalismo jornalístico, o fenômeno do paralelismo político pode, de fato, ser multidimensional [...] (HALLIN \& MANCINI, 2012, p. 295 - tradução nossa)
\end{abstract}

A proposta dos autores de pensar a intervenção política do sistema mediático a partir de uma perspectiva multidimensional nos parece promissora. Tal proposta se mostra especialmente útil quando levamos em conta que ela encontra fortes justificativas na pesquisa comparativa nos estudos do jornalismo.

Esse foi 0 caso revelado pelas 1.800 entrevistas conduzidas por Hanitzsch e colegas (2011) em 18 países, dentre eles o Brasil. De acordo com os dados fornecidos pelos autores, os jornalistas brasileiros, em comparação aos colegas estadunidenses e alemães, demonstram o nível mais alto de concordância de que é seu papel "advogar por transformação social" (p.292). Os autores encontraram esse tipo de liderança advocatícia também em outros jornalistas de países em desenvolvimento e com regimes democráticos em consolidação. Assim, os pesquisadores sustentam que há uma tendência em direção ao intervencionismo "entre jornalistas de sociedades em desenvolvimento e democracias em transição" (HANITZSCH et al, 2011, p.281).

0 estágio de questionamento atual em estudos em jornalismo indica, dessa forma, que é necessário analisar a relação entre 0 sistema mediático e as elites políticas não mais a partir de vinculações permanentes e estáveis entre esses setores. Passa a ser mais fecundo, portanto, compreender as circunstâncias e variáveis que aumentam ou diminuem o nível de intervenção política do sistema mediático na vida pública.

\section{0 caráter ativo e advocatício como referências de análise}

Os argumentos de Albuquerque se mostram promissores para explicar fenômenos que as variáveis propostas por Hallin \& Mancini não dão conta. No entanto, a própria noção de "caráter ativo" das práticas jornalísticas tem sido conceituada de diversas formas e, até agora, não 
há uma descrição consensual e consolidada dos elementos que constituem a forma e a intensidade com que a prática jornalística intervém na vida política. A proposta de Albuquerque (2012), por exemplo, propõe realizar esse tipo de análise a partir de uma sobreposição de dimensões que Donsbach e Patterson (2004) argumentam ser independentes. Isso porque Albuquerque (2012, p.91) descreve a prática do jornalismo brasileiro em seu caráter "ativo" nos seguintes termos:

(a) tomada de posições políticas;

(b) foco da atenção mais direcionada ao presidente do que à política partidária;

(c) fornecimento de informação e interpretação; e

(d) maior ênfase nos aspectos administrativos do governo do que na política partidária.

Essa abordagem analítica pode, contudo, ofuscar as distintas características que compõem o nível de intervenção política do sistema mediático. Nesse sentido, Donsbach e Patterson (2004) sustentam que a noção de "um jornalismo ativo" deve ser mantida separada da compreensão de "um jornalismo advocatício". Enquanto o primeiro "atuaria mais plenamente como um participante do debate, enquadrando, interpretando, ou investigando os assuntos políticos" (grifo e tradução nossos), o profissional ligado ao jornalismo advocatício - ou mesmo militante - seria "aquele que atua com base em posicionamentos políticos na forma correspondente a de um ator político", o que significa que ela ou ele "toma partido e faz isso de uma forma consistente, substancial e agressiva" (p. 265).

Essa diferença, ainda que pouco detalhada e desenvolvida, parece produtiva, pois ela sinaliza a existência de diversas formas com as quais as práticas jornalísticas podem intervir no jogo político e no debate público. Formas que guardam contribuições diferentes para o processo democrático e que também podem variar de modo distinto entre e internamente nos sistemas mediáticos.

A esse respeito, a contribuição do jornalismo investigativo em revelar informações que, de outro modo, não emergiriam à esfera pública (prática relacionada ao caráter ativo) não pode ser simplesmente subsumida à prática de emitir opinião e juízo de valor sobre atores políticos (relacionada ao caráter advocatício). No estudo desenvolvido por Wessler e colegas (2008), por exemplo, insumos interpretativos ou opinativos sobre fatos e atores políticos foram mensurados em dez sistemas mediáticos europeus. Esse tipo de insumo apresentou grande variação no jornalismo online desses países, indo de 0 a $15 \%$.

Já a prática do jornalismo investigativo de se colocar como vigia crítico do poder seria "praticamente universal entre as democracias ocidentais" (HALLIN \& MANCINI, 2004, p.03). Ela integra, portanto, a função de "cão de guarda" operada pelo sistema dos media e tão cara à deontologia do jornalismo político em sociedades democráticas (ver AZEVED0, 2006, 
p.110; MARQUES \& MIOLA, 2010, p.10-11). Essa

função tende a abrigar, irremediavelmente, a produção de insumos críticos e interpretativos, exatamente como prevê 0 caráter advocatício. Além disso e ultrapassando esse caráter, o jornalismo investigativo produz informação nova e desvela fatos que atores políticos, muitas vezes, tentam manter em segredo. Desse modo, ele explora a espinha dorsal que sustenta a ampliação da publicidade nas sociedades democráticas: a informação de bastidores, especialmente aquela que serve tanto para gerar atenção pública como para constranger autoridades e atores a prestarem contas ao público. Tal prática, frequentemente, desencadeia várias produções jornalísticas em série dentro daquilo que pode abranger o "escândalo político".

Tendo em vista essas diferenças ilustrativas entre "jornalismo investigativo" e "jornalismo de opinião", propõe-se investigar um estudo de caso que possa responder às seguintes perguntas de pesquisa:

(a) Quais elementos coexistentes nas acepções de jornalismo ativo e advocatício são capazes de descrever com maior fidedignidade 0 perfil do sistema mediático brasileiro?

(b) Esses elementos evidenciam os limites da noção de "paralelismo político" para se descrever o nível de intervenção política desse sistema?

(c) Esses elementos se apresentam distribuídos de modo homogêneo ou eles se expressam em intensidades distintas ao longo do sistema mediático?
Para dar respostas a essas indagações, nossa pesquisa analisou a cobertura da COP-15. Na próxima seção, esclarecemos as razões que levaram à escolha desse evento e o modo pelo qual as perguntas de pesquisa foram operacionalizadas em procedimentos metodológicos.

\section{Estudo de caso e métodos}

0 primeiro desafio metodológico para responder às nossas indagações consiste em selecionar instâncias centrais do sistema informativo dos media. Por "central", não se deve entender elementos representativos desse sistema em termos populacionais (o que tenderia a uma amostra aleatória), mas, sim, pontos de concentração e distribuição de características específicas que sejam relevantes a esta pesquisa. Dentre as características em questão, interessanos investigar produtos jornalísticos que concentrem visibilidade pública e qualidade jornalística. Daí que a análise da cobertura da COP-15 se deu em função do seu:

(a) centro de visibilidade pública;

(b) centro de qualidade jornalística.

Com relação ao primeiro, trata-se daquilo que Wilson Gomes definiu como sendo o ponto demograficamente mais relevante em que "ações e pessoas são representadas diante de uma larga atenção pública concentrada" (GOMES, 2009, p.185). Trata-se, no caso do jornalismo brasileiro, do Jornal Nacional. 
Já o segundo centro se refere àquilo que a literatura especializada tem chamado de imprensa de referência (reference press ou quality press) e que, sob alguns aspectos, tem presumidamente mais credibilidade e influência na formação da opinião pública. Selecionamos a FSP como correspondente a esse centro pelo fato de ser um dos veículos mais tradicionais nesse setor, por oferecer seu conteúdo digitalmente em versãofac-simile e por ter a maior circulação nesse nicho no ano da cobertura da COP-15, i.e., em $2009^{3}$.

Sob esses parâmetros, a cobertura da COP-15 foi submetida a uma análise interpretativa e de conteúdo através do JN $(n=21)$ e da FSP $(n=65) .0$ período selecionado foi o mesmo do evento: 07 a 19 de dezembro de 2009, 0 que totalizou 12 dias de cobertura. A seleção da COP-15 se justifica inclusive pelo fato de essa COP ter sido a conferência do clima que mais cobertura teve no JN nos últimos anos, estabelecendo, desse modo, condições adequadas para uma pesquisa comparada - dia a dia - com a FSP. Esta, por sua vez, oferece maior diversidade e volume de matérias.

De modo a controlar essas diferenças, trabalhamos apenas com notícias ou reportagens. Ou seja, editorais, charges, entrevistas e colunas assinadas não integram o corpus deste trabalho. Sob esse critério e outros de caráter formal, a pesquisa foi censitária. Isso implica que todas as matérias encontradas, sob tais critérios, foram codificadas e analisadas.

Com 0 objetivo de identificar tanto as características do caráter advocatício quanto as do caráter ativo do jornalismo, estabelecemos duas variáveis compostas: escrutínio público e publicidade ampliada, respectivamente.

A variável composta escrutínio público corresponde à avaliação crítica (desfavorável) ou positiva (favorável) que as fontes - incluindo os próprios jornalistas - fazem de atores políticos. Além desse caráter positivo ou negativo, também foi identificada a distribuição quantitativa desse escrutínio. Com essa distribuição, desenvolvemos um levantamento do viés partidário dos atores mais criticados e bem avaliados. Ademais, 0 caráter advocatício é definido por Donsbach e Patterson como algo que se estabelece de forma "substantiva, consistente e agressiva". Tendo isso em vista, também conduzimos uma análise interpretativa sobre 0 nível de agressividade e contundência com que o escrutínio público foi realizado na cobertura.

A segunda variável composta - publicidade ampliada - diz respeito ao caráter ativo do jornalismo na medida em que ele fornece informações que, apesar de serem frequentemente produzidas por atores políticos, são desveladas 
pela prática jornalística. Chamamos aqui de "desvelamento" a prática de o jornalismo em revelar e fazer circular informações que não podem ser encontradas nos meios oficiais de comunicação dos governos e de instituições políticas. 0 objetivo de operacionalizar esta variável é verificar se, como e em que medida a cobertura de cada veículo em questão amplia a publicidade produzida pelas fontes oficiais de informação. Para isso, a variável em questão foi produzida a partir da agregação de três outras variáveis: informação extraoficial, informação de bastidores e escândalo.

A informação extraoficial mensura informações "exclusivas" produzidas pelo jornalismo, mas que não necessariamente foram publicadas à revelia das fontes que a produziram. Elas são consideradas "exclusivas", pois elas não puderam ser encontradas na página oficial da organização que conduziu a COP-15 (a UNFCCC). Nesta página, encontram-se vídeos em que é possível ver e ouvir as declarações dos países participantes nas sessões formais. Ao focalizarmos nas declarações feitas em nome do Brasil, pôde-se identificar qual foi a posição oficial apresentada pelo país nas sessões da COP-15. Em seguida, comparamos os proferimentos feitos nestas sessões com os reportados na cobertura jornalística. Consideramos toda informação adicional aí encontrada como sendo "informação extraoficial".

A variável "informação de bastidores", por sua vez, refere-se a toda informação que, na cobertura, seja explicitamente classificada como "vazamento" ou com outras noções que indiquem que a informação foi tornada pública sem 0 consentimento de quem a produziu.

A variável "escândalo", por sua vez, corresponde a insumos na cobertura que sugerem choque público ou forte desaprovação moral em relação a uma ação ou declaração de um ator político. Essas declarações ou ações podem envolver qualquer ator e não apenas os representantes políticos que falam em nome do Brasil. Um escândalo pode ser também fruto do vazamento de informações de bastidores. Para diferenciar um do outro, deve-se levar em conta que, enquanto as informações de bastidores geralmente não são acompanhadas de explícita desaprovação moral, o escândalo 0 é. Dessa forma, "escândalo" foi codificado apenas quando houve menção explícita a uma reação generalizada ou forte desaprovação sobre 0 fato ou evento relatado. Também codificamos a variável em questão quando o próprio material jornalístico classifica um determinado vazamento como sendo um "escândalo".

Além das duas variáveis compostas descritas anteriormente, também produzimos uma variável denominada de "transparência oficial", a qual forneceu dados sobre a intensidade com que as matérias reportaram o discurso oficial encontrado nas sessões da COP-15. Essa variável indica, desse modo, o lado oposto de um jornalismo ativo/ advocatício, ou seja, o jornalismo passivo. Este se contenta em reportar o discurso oficial. 
Para gerar a quantificação dessas variáveis, contabilizou-se a quantidade de ocorrências de cada proferimento em uma matéria.

Posteriormente, foi produzida uma média de cada variável presente na matéria, mas também nas outras unidades de análise agregadas (cobertura do JN x cobertura da FSP). A quantificação de cada variável se deu em termos proporcionais e evitou, consequentemente, resultados influenciados pela quantidade absoluta.

No entanto, é preciso enfatizar que os princípios metodológicos de validade, confiabilidade e replicabilidade só podem ser plenamente atendidos por essa pesquisa mediante a consulta ao seu livro de códigos e aos bancos de dados, tanto os originais como os codificados. Encorajamos os pesquisadores e leitores a solicitarem acesso a tais materiais através dos correios eletrônicos dos autores deste trabalho.

\section{Resultados}

A variável "transparência oficial" é um indicador do caráter passivo da cobertura, e a diferença das respectivas médias da FSP e do JN foi muito pequena. Na análise de variância Anova disponível na Tabela 1, é possível observar que a força da diferença $\left(F^{\prime}\right)$ entre as duas coberturas foi a segunda menor entre as três variáveis agregadas em destaque (em negrito).

A menor força da diferença entre as coberturas ocorreu em relação à publicidade ampliada.
Não obstante, pode-se também verificar que houve diferenças substantivas quanto à variável informação extraoficial e com relação à informação de bastidores. Enquanto nesta o JN ofereceu um nível maior, naquela foi a FSP a que disponibilizou a maior intensidade da variável em questão. Aliás, informação extraoficial foi a variável cuja força da diferença $(2,17)$ foi a $2^{\text {a }}$ maior entre todas as variáveis (incluindo as compostas) aqui mensuradas.

A maior foi relativa ao escrutínio público favorável $(2,25)$. Esta variável indica que a FSP apresentou maior intensidade de elogios ou aprovações relativas a atores políticos do que $0 \mathrm{JN}$. Não obstante, é oportuno atentar que os dois veículos apresentaram um volume maior de críticas do que de elogios. É possível verificar, portanto, um desempenho de ambos os produtos jornalísticos mais próximo ao ideal de "watchdog" do que ao de mídia chapa branca, i.e., "lapdog".

No entanto, o caráter passivo, na cobertura do JN, foi maior quando se leva em conta que a média de transparência oficial $(0,29)$ foi a maior entre as três variáveis analisadas, em que escrutínio público alcançou a média de 0,20 e publicidade ampliada, 0,23. A FSP, por sua vez, apresentou proporcionalmente mais escrutínio público $(0,37)$ do que transparência oficial e publicidade ampliada (0,26 em ambas). A propósito, escrutínio público foi a variável agregada cuja força da diferença entre as médias foi a maior entre as duas coberturas analisadas. 
Tabela 1: Análise de variância (Anova) da cobertura (FSP x JN) da COP-15

\begin{tabular}{|c|c|c|c|c|c|c|}
\hline & \multicolumn{2}{|c|}{ FSP $(n=65)$} & \multicolumn{2}{|c|}{ JN (n = 21) } & \multicolumn{2}{|c|}{ ANOVA $^{a}$} \\
\hline & Média & $d p$ & Média & $d p$ & $\boldsymbol{F}$ & sig. \\
\hline Transparência oficial $(p)$ & 0,26 & 0,57 & 0,29 & 0,80 & 0,06 & 0,81 \\
\hline Escrutínio público (ad) & 0,37 & 0,59 & 0,20 & 0,41 & 1,48 & 0,22 \\
\hline Favorável & 0,11 & 0,29 & 0,01 & 0,07 & 2,25 & 0,13 \\
\hline Contrário & 0,26 & 0,47 & 0,19 & 0,40 & 0,37 & 0,54 \\
\hline Publicidade ampliada ( $a t$ ) & 0,26 & 0,48 & 0,23 & 0,63 & 0,05 & 0,81 \\
\hline Extraoficial & 0,22 & 0,47 & 0,06 & 0,21 & 2,17 & 0,14 \\
\hline Bastidores & 0,03 & 0,13 & 0,14 & 0,61 & 1,92 & 0,16 \\
\hline Escândalo & 0,01 & 0,04 & 0,02 & 0,09 & 0,79 & 0,37 \\
\hline
\end{tabular}

Observadas essas diferenças, cabe agora verificar 0 viés partidário desse escrutínio realizado pela cobertura da COP-15. Como mostra a Figura 1, os três atores mais criticados em sentido de reprovação foram o governo da Dinamarca, dos EUA e da China. 0 quarto e o quinto ator mais criticado foram, respectivamente, os negociadores Michael Z. Cutajar e Luiz F. Machado, os quais estiveram entre os atores também mais bem avaliados (ver Figura 2).

Enquanto Cutajar foi o mais bem avaliado, Machado foi o terceiro. A maior parte da proeminência desses atores foi produzida pela matéria da FSP "EUA defendem mais pressão em emergentes", publicada no dia 12 de dez. 09. Nessa matéria, encontram-se avaliações de diversos atores sobre a proposta de acordo para o desfecho da COP-15. Exemplo para avaliação desfavorável: “Ontem Japão e Austrália se opunham ao texto de Cutajar e Figueiredo". Exemplo para favorável: "Ainda assim, ele [Luiz F. Machado] classificou a recepção do texto como, 'em geral, boa'". Essa proposta de texto foi redigida justamente pelos negociadores em questão. Como essas avaliações se dividem tanto favorável como desfavoravelmente, não fica comprovada a existência de um viés partidário ao modo que a variável "paralelismo político" prevê.

A crítica concentrada em torno da

Dinamarca também não poderia ser explicada satisfatoriamente pela concepção clássica de "paralelismo político". Isso porque não existe qualquer correlação cabível entre a vinculação política dos jornais analisados e a crítica ao ator político em questão, o qual só se mostrou relevante para a cobertura pelo fato de ter sido o país e governo que organizou 
Figura 1: Atores criticados na cobertura da COP-15

Atores criticados na cobertura da COP-15

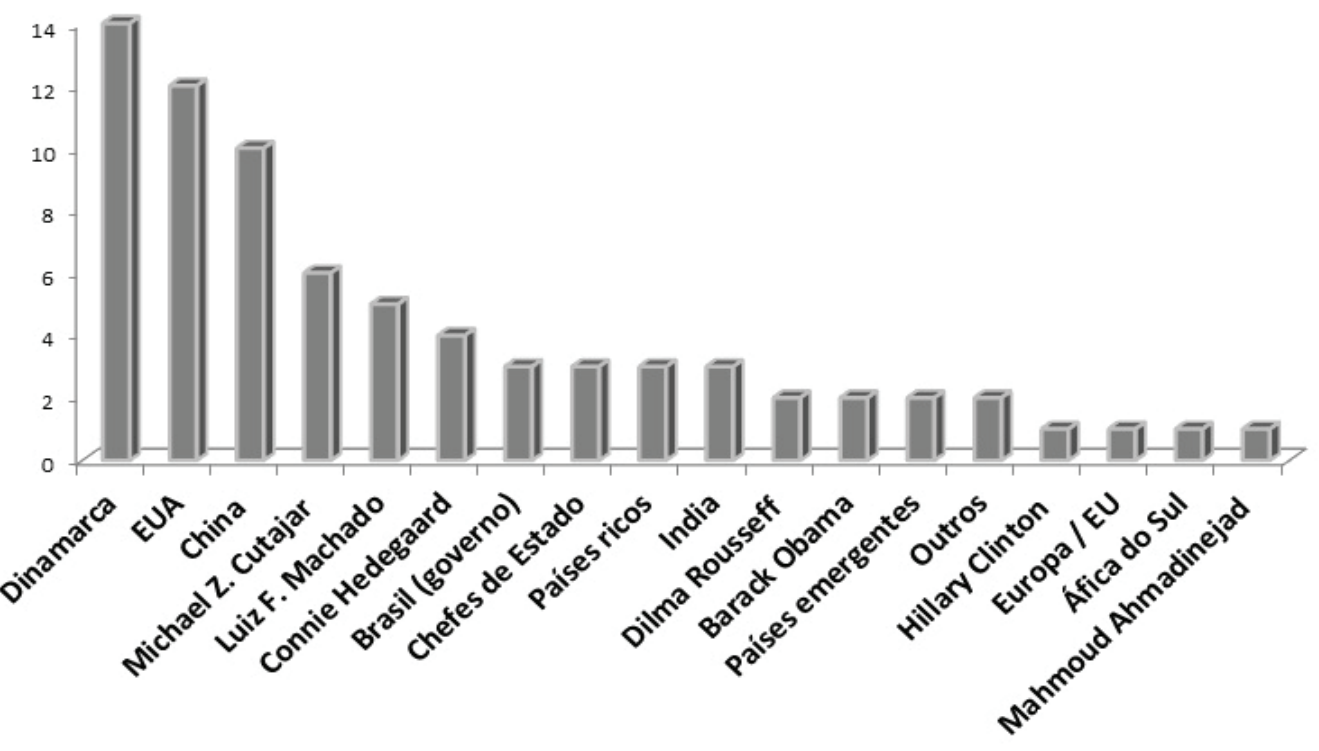

Figura 2: Atores positivamente avaliados na cobertura da COP-15

Atores positivamente avaliados na cobertura da COP-15

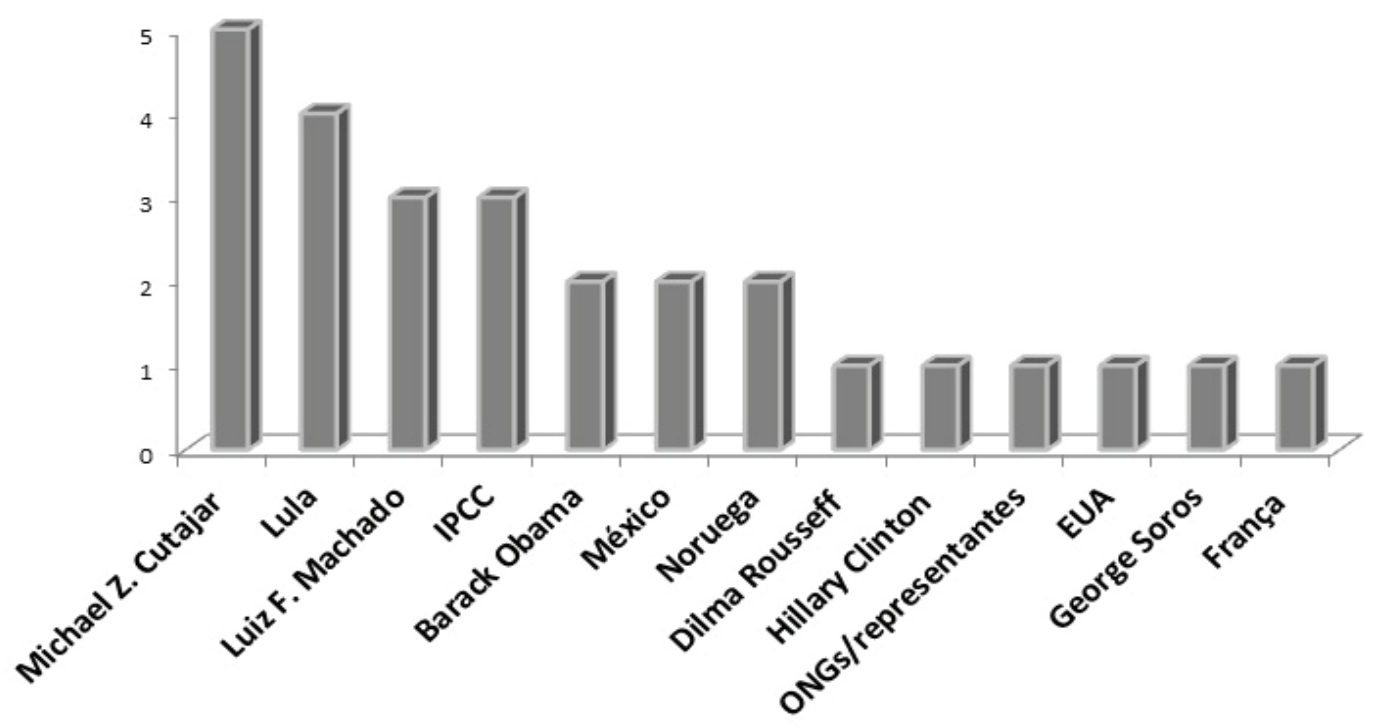


a COP-15. A Dinamarca foi criticada por diversos atores, especialmente pelos países em desenvolvimento, por ter conduzido as negociações de forma pouco transparente e inclusiva. Um exemplo pode ser encontrado na matéria "Brasil pede corte de $\mathrm{CO}_{2}$ aos ricos, sem meta para os pobres", publicada pela FSP em 09 de dez. 09. Na matéria, há, entre outros, o seguinte proferimento com escrutínio público desfavorável: "O documento do país anfitrião da conferência [a Dinamarca], que vazou anteontem, foi criticado". Aqui, a propósito, além do escrutínio em questão, existe também informação de bastidores (documento vazado), demonstrando que a pesquisa foi sensível em analisar separadamente duas práticas jornalísticas que estão subsumidas na concepção de "jornalismo ativo" explicitada por Albuquerque (2012).

Com relação à crítica concentrada em torno da China e dos EUA, a análise anterior parece ser válida também para estes atores. Eles, por serem os maiores emissores atuais de gases que causam o efeito estufa, acabam recebendo maior atenção crítica. Não se trata, portanto, de antiamericanismo nem aversão à sociedade chinesa. Já a concentração de apreciação positiva em torno de Lula, além de não poder ser explicada por um viés partidário, contraria a expectativa muito comum na esfera pública de que a grande mídia brasileira teria um viés anti-petista, anti-lulista, etc.
A propósito, o JN não produziu uma só crítica, seja favorável ou desfavorável a atores brasileiros. Isso (a crítica), no pouco que ocorreu, concentrou-se em torno da China e dos EUA. Além dessa menor diversidade de atores criticados, a forma com que as críticas foram expressas se demonstra ser menos agressiva do que a FSP. Um exemplo é encontrado na edição do dia 11 de dez. 09, na qual se diz: "Estados Unidos e China, que juntos emitem $40 \%$ dos gases que provocam 0 efeito estufa, se acusam mutuamente de fazer pouco. E pelo menos nisso, os dois parecem estar certos". A FSP, por seu turno, demonstrou-se menos hesitante na hora de produzir suas avaliações críticas: "EUA, China, Brasil, Índia e África do Sul fecham acordo tímido, sem metas de redução de $\mathrm{CO}_{2}{ }{ }^{4}$

\section{Discussão}

Nessa pesquisa, tentamos esclarecer três perguntas. Na primeira, estivemos interessados em saber quais elementos coexistentes nas acepções de jornalismo ativo e advocatício seriam capazes de descrever com maior fidedignidade 0 perfil do sistema mediático brasileiro. A segunda, por sua vez, questionava quais desses elementos evidenciam os limites da noção de "paralelismo político" para se descrever o nível de intervenção política desse sistema. A última trouxe à baila se esses elementos se apresentariam distribuídos de 
modo homogêneo ou se eles se expressariam em intensidades distintas.

Com relação à primeira, os resultados indicam o caráter ativo e passivo como praticamente constante ao longo de pontos centrais do sistema mediático brasileiro. Ou seja, o caráter ativo e, ao mesmo tempo, "oficialista" seriam marcas capazes de explicar, em termos gerais, as características desses pontos. Esses resultados corroboram evidências levantadas por outras pesquisas (CAMPOS, 2012, GOMES, 2009, MIOLA, 2012), especificamente no que se refere à marca oficialista em tela.

No que diz respeito à segunda pergunta da pesquisa, foi possível identificar que a dimensão advocatícia é a noção que melhor evidencia os limites da noção de "paralelismo político" para descrever, com precisão, o perfil do sistema mediático brasileiro. Isso porque, mesmo quando toma posição política clara, o jornalismo de centros desse sistema não o faz de maneira partidária. Isso vai ao encontro do que tem argumentado Albuquerque $(2005,2012)$.

Contudo, os esforços de responder à terceira questão indicaram que 0 caráter advocatício não está distribuído igualmente entre os centros do sistema mediático brasileiro aqui estudados. Tanto quanti como qualitativamente, foi possível perceber que a FSP se posicionou mais em relação aos atores políticos do que 0 JN. Sob rigor estatístico, não é uma diferença quantitativamente significativa, mas é substantiva, já que a pesquisa foi censitária para um estudo de caso. Ademais, nossos resultados vão na mesma direção da pesquisa de Miola (2012, p.244), a qual demonstrou o papel de ator político desempenhado pela imprensa brasileira no debate sobre a criação da EBC, sendo que essa característica se apresentou com maior ênfase nas revistas semanais Veja e Carta Capital.

Uma das contribuições desta pesquisa a esta literatura é prover evidências em favor de um quadro de distribuição da força da intervenção política do jornalismo no sistema mediático brasileiro. Nesse quadro, essa intervenção, em seu caráter advocatício, tende a ser mais forte no centro da imprensa de revista semanal (na Veja) e mais fraco em seu centro de visibilidade pública (0 JN). Como setor intermediário, estaria o centro de qualidade jornalística (a FSP).

Outra contribuição consiste em identificar as nuances que estão por trás da ideia de "intervenção política" das práticas jornalísticas. A esse respeito, demonstrou-se ser produtiva a análise orientada pela diferença entre "jornalismo ativo" e "jornalismo advocatício".

Pesquisas adicionais, no entanto, são necessárias, uma vez que esta é, ao que nos consta, a primeira que operacionaliza essa distinção em termos de análise interpretativa e de conteúdo. Para tanto, seria produtivo expandir essa combinação de métodos a 
coberturas de eventos nacionais, já que os resultados desta pesquisa decorrem de um evento de política internacional. Ademais, outras formas de amostra que não censitárias, inclusive com maior escala temporal e de matérias, testariam os achados deste trabalho de forma mais abrangente.

\section{Considerações Finais}

Neste trabalho, buscamos revelar a heterogeneidade de fenômenos subjacentes à ideia de "intervenção política" das práticas jornalísticas. A esse respeito, demonstrou-se ser produtiva a análise orientada pela diferença entre "jornalismo ativo" e "jornalismo advocatício". Entre outros, tal diferença foi capaz de descrever com relativa fidedignidade 0 desempenho de centros do sistema mediático brasileiro.

Outra contribuição de nosso trabalho refere-se ao levantamento de evidências em favor de uma escala do caráter advocatício do jornalismo ao longo dos centros do sistema mediático brasileiro. Nessa escala, o centro mais fraco seria o JN. Em posição intermediária, estaria a FSP. 0 centro mais forte, por sua vez, seria a Veja. Mas esta última não foi evidenciada por nossa pesquisa, mas por pesquisas anteriores. Dadas essas limitações, pesquisas futuras poderiam realizar uma comparação entre todos os centros em questão em uma escala temporal maior, com mais matérias e que envolvessem temas e controvérsias de âmbito nacional.
Caso essa escala de caráter advocatício venha a se confirmar, é oportuno perceber sua variação de acordo com uma perspectiva sistêmica, na qual outros elementos tão caros à democracia também tendem a variar no debate público mediado. Sob essa perspectiva, é importante salientarmos - na mesma linha do argumento de Marques e Miola (2010) que todos os elementos aqui identificados sob os conceitos de jornalismo passivo, ativo e advocatício são importantes para o processo democrático e devem, portanto, ser distribuídos de acordo com as necessidades da comunidade política. Uma vez que esta é, em sociedades complexas e descentradas, plural e altamente diferenciada, também é de se esperar que essas características que compõem o nível de intervenção política do jornalismo apresentem alto grau de pluralidade e diferenciação. Desse modo, não é prudente se conceber uma métrica normativa de cada dimensão em tela para matérias isoladas ou mesmo em coberturas de um só veículo de comunicação. A distribuição normativa dessas medidas deveria se dar ao longo do sistema mediático e de acordo com a diversidade de públicos submetidos a condições econômicas e sociopolíticas em constante transformação. Por isso, além de réguas sistêmicas, são necessários olhos sensíveis à dimensão qualitativa que envolve as práticas jornalísticas para cada público, ambiente e momento histórico.

\section{Referências}

ALBUQUERQUE, A. Another 'Fourth Branch': Press and political culture in Brazil. Journalism (London), London, v. 6, n.4, 2005, p. 486-504. 
ALBUQUERQUE A. On Models and Margins:

Comparative Media Models Viewed from a Brazilian

Perspective. In: HALLIN DC and MANCINI P (eds.)

Comparing Media Systems Beyond Western World.

Cambridge: Cambridge University Press, 2012, p.72-95.

AZEVED0, F. Mídia e Democracia no Brasil: relações entre 0 sistema de mídia e 0 sistema político. Opinião

Pública, 12 (1), 2006, p.88-113

CARD0S0, F.M. Mídia e mudanças climáticas no

Brasil entre demandas por crescimento econômico

e desenvolvimento sustentável. Dissertação de

mestrado, UFMG, PPGcom, Belo Horizonte, 2013.

DONSBACH, W., \& PATTERSON, T. E. (2004).

Political news journalists. Comparing political

communication: Theories, cases, and challenges, 251-270.

GOMES, W. Audioesfera política e visibilidade pública: os atores políticos no Jornal Nacional. In: GOMES, Itania M. M.. (Org.). Televisão e realidade. Salvador: EDUFBA, 2009, p. 175-222.

HALLIN, D \& MANCINI, P. Comparing Media Systems. Cambridge, UK: Cambridge University Press, 2004.

HALLIN, D \& MANCINI, P (eds.) Comparing Media

Systems Beyond the Western World, Cambridge

University Press, 2012.

HANITZSCH, T., et al. Mapping journalism cultures across nations: A comparative study of 18 countries. Journalism Studies, v.12, n. 3, 2011, p.273-293.

MAIA, R. C. M.. Mediated deliberation and dilemmas of consolidating democracy in Brazil: the 2005 referendum for banning firearm Sales, International Journal of Press/Politics, v.14, 2009, p.313-334.

MARQUES, F.P.J. \& MIOLA, E. Deliberação Mediada: uma tipologia das funções dos media para a formação do debate público. In Estudos em Comunicação n ${ }^{07}$ Volume 1, 1-28, 2010, p.01-28.
MIOLA, E. Sistema deliberativo: tensões entre interesses públicos e privados. Tese de doutorado, UFMG, PPGcom, Belo Horizonte, 2012.

WESSLER, H.; et al (2008). Comparing media systems and media content: Online newspapers in ten Eastern and Western European countries. Journal of Global Mass Communication, 1(3/4), 165. 


\section{COP-15 under media spotlight: different modes and levels of journalistic political intervention along the Brazilian media system}

\section{Abstract}

This paper offers evidence for the understanding that the Brazilian case would be an example of the shortcomings from the variable "political parallelism". This would be the case since the Brazilian media system presents strong active and advocate traits in a way that the variable "political parallelism" does not conceive. This research, on the one hand, provides evidence in favor of this argument, specifically concerning its centers of visibility and quality (JN and FSP respectively). Secondly, the data also indicates that these traits assume different modes and levels between the centers at stake. From FSP $(n=65)$ to JN $(n=$ 21 ) we were able to find substantial differences in the quantity and quality of the advocate role journalistic practices for the COP-15 coverage. At the same time, its active role remained stable. Theoretical and methodological implications for future research are discussed.

\section{Keywords}

Political parallelism. COP-15. Media system. Brazilian journalism.

\section{La COP-15 en atención de los medios:} los modos y niveles de intervención política en los medios de comunicación periodismo sistema brasileño

\section{Resumen}

La variable "paralelismo político" ha sido recurrente en el análisis comparativo de los sistemas de medios de comunicación. Sin embargo, recientemente ha sido objeto de varias críticas. Para apoyar este tipo de defensa el sistema de medios de comunicación brasileños y de los países en desarrollo se ha hecho referencia como ejemplo paradigmático de una forma activa, pero que no son parte necesariamente la intervención política político. Esta investigación, por un lado, proporciona evidencia empírica en esta dirección, especialmente para los centros de la visibilidad y la calidad periodística del sistema mediático brasileño (JN y FSP, respectivamente). En segundo lugar, también se ha demostrado que el rendimiento tiene diferentes modos e intensidades entre los centros interesados. Entre FSP $(n=65)$ y JN $(n=21)$ se reveló diferencias sustanciales en la cantidad y calidad de advocatício papel de la práctica periodística en la cobertura de la COP-15. Al mismo tiempo, el carácter activo se mantuvo estable. Se discuten las implicaciones teóricas y metodológicas para la investigación futura.

\section{Palabras clave}

Paralelismo político. COP-15. Sistema de medios de comunicación. Periodismo brasileño 


\section{Expediente}

A revista E-Compós é a publicação científica em formato eletrônico da Associação Nacional dos Programas de Pós-Graduação em Comunicação (Compós). Lançada em 2004, tem como principal finalidade difundir a produção acadêmica de pesquisadores da área de Comunicação, inseridos em instituições do Brasil e do exterior.

\section{E-COMPÓS I www.e-compos.org.br I E-ISSN 1808-2599}

Revista da Associação Nacional dos Programas de Pós-Graduação em Comunicação.

Brasília, v.18, n.1, jan./abri.. 2015.

A identificação das edições, a partir de 2008, passa a ser volume anual com três números.

\section{CONSELHO EDITORIAL}

Alexandre Rocha da Silva, Universidade Federal do Rio Grande do Sul, Brasil Alexandre Farbiarz, Universidade Federal Fluminense, Brasil Ana Carolina Damboriarena Escosteguy, Pontifícia Universidade Católica do Rio Grande do Sul, Brasil

Ana Carolina Rocha Pessôa Temer, Universidade Federal de Goiás, Brasil Ana Regina Barros Rego Leal, Universidade Federal do Piauí, Brasil André Luiz Martins Lemos, Universidade Federal da Bahia, Brasil Andrea França, Pontifícia Universidade Católica do Rio de Janeiro, Brasil Antonio Carlos Hohlfeldt, Pontifícia Universidade Católica do Rio Grande do Sul, Brasil

Arthur Ituassu, Pontifícia Universidade Católica do Rio de Janeiro, Brasil Álvaro Larangeira, Universidade Tuiuti do Paraná, Brasil Ângela Freire Prysthon, Universidade Federal de Pernambuco, Brasil César Geraldo Guimarães, Universidade Federal de Minas Gerais, Brasil Cláudio Novaes Pinto Coelho, Faculdade Cásper Líbero, Brasil Daisi Irmgard Vogel, Universidade Federal de Santa Catarina, Brasil Daniela Zanetti, Universidade Federal do Espírito Santo, Brasil Denize Correa Araujo, Universidade Tuiuti do Paraná, Brasil Eduardo Antonio de Jesus, Pontifícia Universidade Católica de Minas Gerais, Brasil

Eduardo Vicente, Universidade de São Paulo, Brasil

Elizabeth Moraes Gonçalves, Universidade Metodista de São Paulo, Brasil Erick Felinto de Oliveira, Universidade do Estado do Rio de Janeiro, Brasil Francisco Elinaldo Teixeira, Universidade Estadual de Campinas, Brasil Francisco Paulo Jamil Almeida Marques, Universidade Federal do Ceará, Brasil Gabriela Reinaldo, Universidade Federal do Ceará, Brasil Gisela Grangeiro da Silva Castro, Escola Superior de Propaganda e Marketing, Brasil

Goiamérico Felício Carneiro Santos, Universidade Federal de Goiás, Brasil Gustavo Daudt Fischer, Unisinos, Brasil

Herom Vargas, Universidade Municipal de São Caetano do Sul, Brasil
Itania Maria Mota Gomes, Universidade Federal da Bahia, Brasil Janice Caiafa, Universidade Federal do Rio de Janeiro, Brasil Jiani Adriana Bonin, Universidade do Vale do Rio dos Sinos, Brasil José Afonso da Silva Junior, Universidade Federal de Pernambuco, Brasil José Luiz Aidar Prado, Pontifícia Universidade Católica de São Paulo, Brasil Kati Caetano, Universidade Tuiuti do Paraná, Brasil

Lilian Cristina Monteiro França, Universidade Federal de Sergipe, Brasil Liziane Soares Guazina, Universidade de Brasília, Brasil Luíza Mônica Assis da Silva, Universidade de Caxias do Sul, Brasil Luciana Miranda Costa, Universidade Federal do Pará, Brasil Malena Segura Contrera, Universidade Paulista, Brasil Marcel Vieira Barreto Silva, Universidade Federal da Paraíba, Brasil Maria Ogécia Drigo, Universidade de Sorocaba, Brasil Maria Ataide Malcher, Universidade Federal do Pará, Brasil Maria Clotilde Perez Rodrigues, Universidade de São Paulo, Brasil Maria das Graças Pinto Coelho, Universidade Federal do Rio Grande do Norte, Brasil

Mauricio Ribeiro da Silva, Universidade Paulista, Brasil

Mauro de Souza Ventura, Universidade Estadual Paulista, Brasil Márcio Souza Gonçalves, Universidade do Estado do Rio de Janeiro, Brasil Micael Maiolino Herschmann, Universidade Federal do Rio de Janeiro, Brasil Mirna Feitoza Pereira, Universidade Federal do Amazonas, Brasil Nísia Martins Rosario, Universidade Federal do Rio Grande do Sul, Brasil Potiguara Mendes Silveira Jr, Universidade Federal de Juiz de Fora, Brasil Regiane Ribeiro, Universidade Federal do Paraná, Brasil Rogério Ferraraz, Universidade Anhembi Morumbi, Brasil Rose Melo Rocha, Escola Superior de Propaganda e Marketing, Brasil Rozinaldo Antonio Miani, Universidade Estadual de Londrina, Brasil Sérgio Luiz Gadini, Universidade Estadual de Ponta Grossa, Brasil Simone Maria Andrade Pereira de Sá, Universidade Federal Fluminense, Brasil Veneza Mayora Ronsini, Universidade Federal de Santa Maria, Brasil Walmir Albuquerque Barbosa, Universidade Federal do Amazonas, Brasil

\section{COMISSÃO EDITORIAL}

\section{Cristiane Freitas Gutfreind}

Pontifícia Universidade Católica do Rio Grande do Sul, Brasil

Irene Machado

Universidade de São Paulo, Brasil

Jorge Cardoso Filho

Universidade Federal do Reconcavo da Bahia, Brasil

Universidade Federal da Bahia, Brasil

$$
\begin{aligned}
& \text { REVISÃo DE TEXTOS I Press Revisão } \\
& \text { SECRETÁRIA EXECUTIVA I Helena Stigger } \\
& \text { EDITORAÇÃO ELETRÔNICA I Roka Estúdio }
\end{aligned}
$$

COMPÓS I www.compos.org.br

Associação Nacional dos Programas de Pós-Graduação em Comunicação

Presidente

\section{Eduardo Morettin}

Universidade de São Paulo, Brasil

eduardomorettin@usp.br

\section{Vice-presidente}

Inês Vitorino

Universidade Federal do Ceará, Brasil

ines@ufc.br

Secretária-Geral

Gislene da Silva

Universidade Federal de Santa Catarina, Brasil gislenedasilva@gmail.com 